\title{
CFD SIMULATION AND VISUALIZATION BASED INVESTIGATION OF SMALL WIND TURBINE POTENTIAL: A CASE STUDY "NEUER STÖCKACH” FOR STUTTGART
}

\author{
Marcus Brennenstuhl ${ }^{1 *}$, Maximilian von der Gruen ${ }^{1}$, Shubhi Harbola ${ }^{1}$, Athanasios Koukofikis ${ }^{1}$, \\ Rushikesh Padsala ${ }^{1}$, Manuel Schaaf ${ }^{1}$, Volker Coors ${ }^{1}$, Ursula Voss ${ }^{1}$ \\ ${ }^{1}$ Stuttgart University of Applied Sciences, Schellingstr.24, 70174 Stuttgart, Germany \\ marcus.brennenstuhl@hft-stuttgart.de (M.B.), maximilian.vondergruen@hft-stuttgart.de (M.G.), \\ shubhi.harbola@hft-stuttgart.de (S.H.), athanasios.koukofikis@hft-stuttgart.de (A.K.), \\ rushikesh.padsala@hft-stuttgart.de (R.P.),01scma1mvm@hft-stuttgart.de (M.S.), \\ volker.coors@ hft-stuttgart.de (V.K.), ursula.voss@hft-stuttgart.de (U.V.)
}

KEY WORDS: Renewable Urban Electricity, Smart Cities, 3D City Models, Urban Simulation, Small Wind Turbines, CFD Wind Simulation, Web 3D Visualization

\begin{abstract}
:
In the face of climate change and the energy transition that the German federal government is aiming for, all renewable energy potentials need to be tapped. Unfortunately, small wind turbines play a niche role in Germany and most other countries despite the fact, that although they offer advantages as e.g. almost seasonal independent energy production in close proximity to the consumer on the same low-voltage grid level. One reason beside the lower wind speeds that can be expected closer to the ground is, that in comparison to PV (photovoltaic), for which good yield forecasts can be made using global radiation measurements from nearby weather stations or online databases, the yield of small wind turbines, especially in urban areas, can only be forecasted using on-site measurements due to the influence of the surrounding buildings and topography. This method is time-consuming and costly. To address this, within this work a Computational Fluid Dynamics (CFD) simulation based visualization framework for the investigation of the small wind turbine potential is presented. In this specific case the energy supply company EnBW is planning to refurbish the "Neuer Stöckach" urban quarter on the former "Stöckach" company site. As part of the redevelopment, a comprehensive energy concept is planned to integrate renewable energies. In this context the integration of small wind turbines into the energy concept is examined according to this new methodology.
\end{abstract}

\section{INTRODUCTION}

\subsection{General conditions}

To date in Germany and in special within the residential building sector, the application of small-scale PV systems is wide spread. In opposite, small wind turbines are not favoured due to various reasons. As it can be seen in Figure 1, the share of electricity produced by small wind turbines in Germany is neglectable. This occures despite the fact, that regarding renewable electricity generation, wind and PV are the most important and widest spread systems. This has many reasons. One is that small wind turbines are not favoured by law (Schelmer and Denk, 2013). Another is that compared to large wind turbines, the wind efficiency of sites is, especially in urban areas, more difficult to assess, as turbulence is created near the ground by buildings and vegetation. Here, a windy site with free inflow in the main wind direction is necessary (C.A.R.M.E.N. e.V, 2020). Third, the wind speed near the ground is significantly lower than e.g. at hub height of large wind turbines (up to $140-160 \mathrm{~m}$ for modern on-shore low wind turbines). This can be partially counteracted by mounting small wind turbines on top of tall buildings. Due to seasonal differences, especially in combination with heat pumps, small wind turbines can complement or be an alternative to PV systems (Brennenstuhl et al., 2018). Also the increasing demand of e-mobility has to be considered in this context. Like PV systems, small wind turbines offer the additional advantage that generation and consumption

\footnotetext{
* Corresponding author
}

are decentralized at the low-voltage grid level, which reduces the need for power grid expansion or upgrading of the existing infrastructure and thus results in lowers costs. In future rising electricity prices, falling battery storage prices, and the increasing electrification of building heat demand by heat pumps and of the transport sector offer new opportunities and a better economic viability for small wind turbines. This, in conjunction with better yield prediction methods, can make new locations economically viable and increase acceptance.

In this paper, a new prediction method for wind speed and small wind turbine yield in an urban environment is presented based on a case study situated in the city of Stuttgart. There the energy supply company EnBW is planning to refurbish the "Neuer Stöckach" urban quarter on the former "Stöckach" company site. As part of the redevelopment, a comprehensive energy concept is planned with the aim of integrating renewable energies into the neighborhood. Preliminary studies have already been carried out for a large-scale installation of PV modules. EnBW is also interested in integrating small wind turbines into the energy concept as a supplement and showcase project.

The problem is that in comparison to PV, for which good yield forecasts can be made using global radiation measurements from nearby weather stations or online databases, the yield of small wind turbines, especially in urban areas, can normally only be forecasted by relying on on-site measurements due to the influence of the surrounding buildings and topography. This method is time-consuming and costly in comparison to the revenue that can be expected. This is critical due to the fact that for small wind turbines the profit margins are low and the pay- 


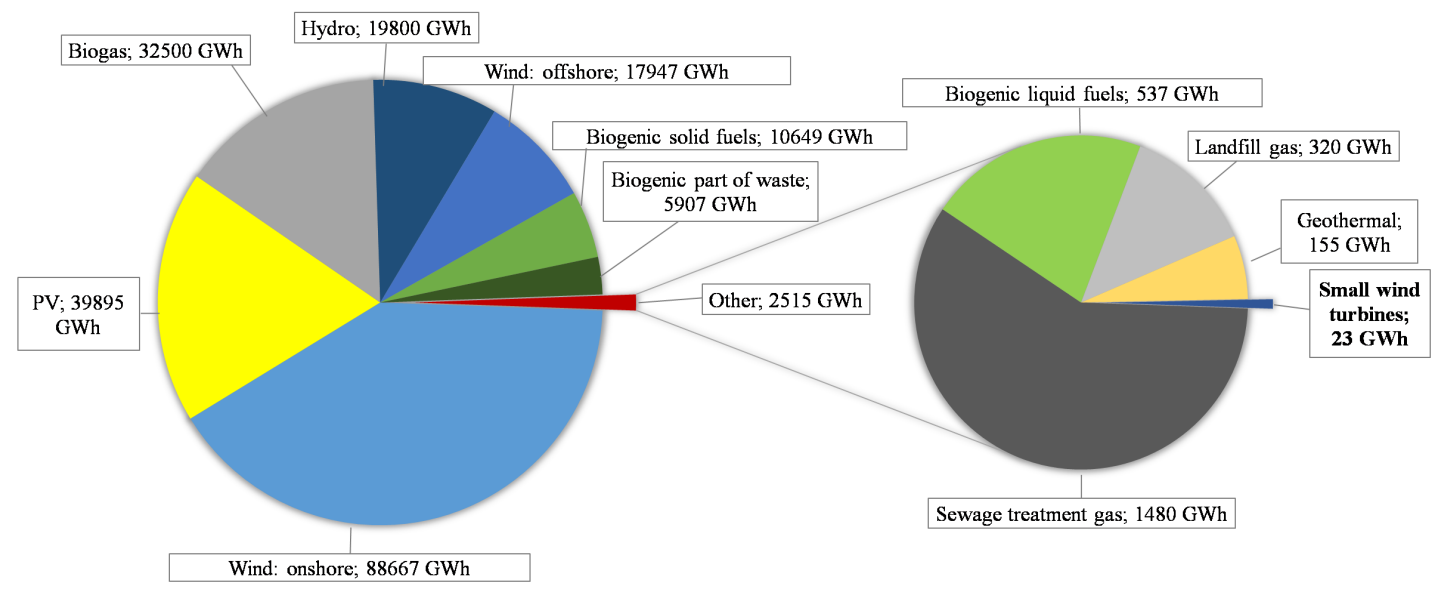

Figure 1. Share of produced electricity by type of plant in Germany 2017 according to (Gehling, 2018).

back time is high. To avoid this, a new CFD simulation-based method of the HFT-Stuttgart is used for the investigation of the small wind turbine potential. Based on available measurement data of wind speed and wind direction from a measuring station in the center of Stuttgart, the expected wind speeds on and above the site will be simulated. Subsequently visualization processes are used to determine the best locations and thus the expected yield is calculated. This approach and it's outcome are presented within this paper in detail.

\subsection{State of the art}

The research community has a great interest in assessing the wind potential in urban areas. In the city of Copenhagen, Beller performed a wind seasonality analysis making use of wind direction and wind velocity readings which were acquired on the roof of H.C. Ørsted Institute building for a period over three years (Beller, 2011). The annual energy production was estimated along with an evaluation of the performance of three small-scale wind turbines virtually exposed to all wind directions found at the roof of the H.C. Ørsted Institute building. Chtibi \& Touzani presented a study of wind energy potential in the area of Morocco based on reports by the Moroccan Ministry of Energy, of the Mines, of the Water and Environment (Chtibi and Touzani, 2019). In addition they performed a correlation analysis between the price and the rated power of vertical axis wind turbines (VAWT) rated below $5000 \mathrm{kWh}$. Wilkinson et al. demonstrated a new approximation approach of computational fluid dynamics in high rise buildings with complex wind interference (Wilkinson et al., 2014). Wang et al. compared and analyzed seven different urban tissues using CFD simulations in the area of Beijing. The numeric results of the simulations were correlated with urban morphology parameters such as floor area ratio, plot ratio, average building height, standard deviation of the building heights, mean building volume, relative rugosity and porosity. The results showed that urban areas with high porosity, high average building height and low floor area ratio can yield more energy from the wind (Wang et al., 2018).

\section{METHODOLOGY}

\subsection{D city model data preparation}

To perform the wind simulation for the study area EnBW Quartier "Neuer Stöckach" in Stuttgart, the first step was to generate the 3D city model of the area. For the proposed work, Open Geospatial Consortium (OGC) standardized open data model of CityGML was chosen. The decision to chose CityGML was influenced by 1) it is an open geodata standard with its application in variety of urban studies (Rossknecht and Airaksinen, 2020), (Bao et al., 2020), (Deininger et al., 2020), 2) the City of Stuttgart already has the CityGML models for the existing building stock of Stöckach and 3) it is possible to integrate and visualize simulation results on a web interface (Schneider et al., 2020). The process to construct the $3 \mathrm{D}$ city model of the study area was motivated by the approach adopted by (Padsala et al., 2020). It is described in the following sections. The overall workflow is showed in Figure 2.

2.1.1 CAD to Shapefile data format using QGIS: The raw urban design data for the study area came in a 2D CAD polyline format. Polylines were converted to building footprint polygons and exported as a polygon shapefile. Since the 2D CAD polylines were already on its correct coordinates, the converted polygon shapefile was given its correct coordinate system of EPSG 31463: DHDN/ 3-degree Gaus Zone 3 (GK3) to match the CityGML dataset of the existing Stöckach building stock's coordinate system provided by the City of Stuttgart. Additionally from the CAD file, building elevation from terrain and building height information (in meters) were extracted and integrated with the shapefile. This is then used further to generate the CityGML building model in its Level of Detail (LoD) 1 .

2.1.2 Shapefile to CityGML LoD1 using FME: The building footprints shapefile from the previous step was imported to Feature Manipulation Engine (FME). FME is an industrially accepted spatial Extract Transform Load (ETL) tool supporting more than 450 data formats for data conversion, integration and management. First a unique ID later to be used to set hierarchy for gml ID and gml parent ID were randomly generated for each building footprint polygon. Then using the building elevation and building height values, building footprints where translated to its correct $\mathrm{Z}$ minimum coordinate and then extruded to generate block models. Block models were then assigned semantic of building as a city object member with a geometry of lod1solid. The output CityGML model can be seen in Figure 3. An example FME workflow to convert shapefile to CityGML LoD1 building models as used in this paper is available on (Transfer portal of the University of Applied Sciences HfT Stuttgart, 2020) 


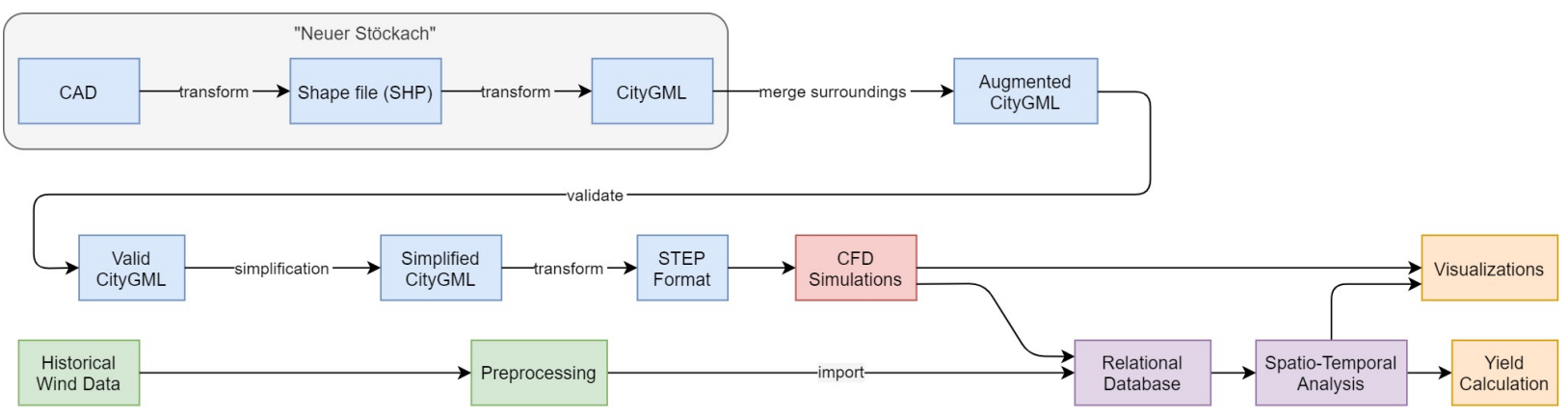

Figure 2. Overall workflow.

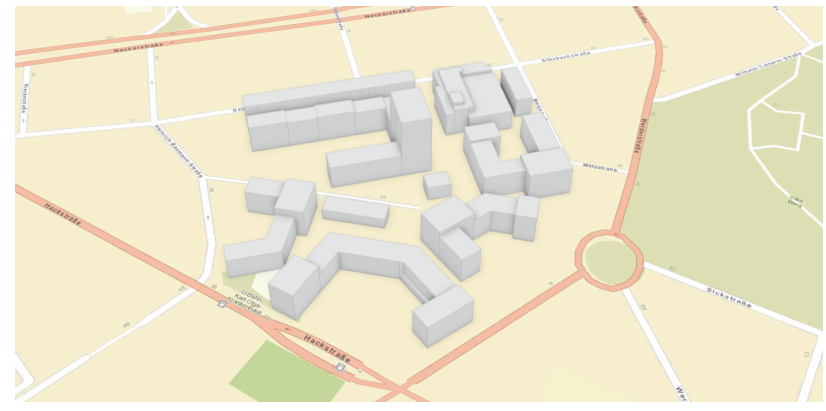

Figure 3. CityGML LoD1-model of the „Neuer Stöckach“ quarter in Suttgart.

2.1.3 Updating the existing Stöckach CityGML data: The City of Stuttgart provided the CityGML dataset for the existing building stock in the Stöckach neighborhood. Together with the building stock 3D geometry, the dataset also contained the terrain and vegetation object of the study area. Therefore, to speed up the data creation process, only the affected existing buildings of the Stöckach area were replaced with the new buildings in CityGML. The terrain and vegetation datasets were left untouched.

\subsection{Wind speed and direction analysis data}

Data from the Stuttgart Mitte measuring station were available from 1987 to June 2020 (Amt für Umweltschutzt Stuttgart, 2021). These data were analyzed in detail with respect to the boundary conditions wind speed and wind direction. To decide which wind directions and speeds should be used for the CFD simulations, the historical wind data of the last three years (2017-2019) were used. The historical wind data were provided by the Environmental Protection Agency in Stuttgart (Amt für Umweltschutzt Stuttgart, 2021). The data preparation and statistical analysis is described in the following steps:

- Reading and merging the Excel files for each year using a Python script

- Excluding columns with irrelevant information

- Removing empty records

- Determining the prominent wind directions and speeds for each year (see Figure 4)

- Additional determination of the wind direction(s) from which wind speeds are to be expected
Wind speed ranges below $2 \mathrm{~m} / \mathrm{s}$ were neglected, since no yield can be expected here for small wind turbines. The most frequently occurring wind speeds were between $2.3 \mathrm{~m} / \mathrm{s}$ and 3.7 $\mathrm{m} / \mathrm{s}$ in the main wind direction $215^{\circ}$. A narrowing down of the considered wind speeds and directions is necessary due to the computational effort of the respective simulation (up to several days on a dedicated high performance system). An overview of the simulated wind speeds and wind directions is given in the following Table 1. An interpolation of the results in between the wind speeds and the wind directions to some degree was carried out in the later part of the workflow.

\begin{tabular}{|c|c|}
\hline Wind direction [0] & Wind speed [m/s] \\
\hline 215 & $1.25,2.25,3.5,4.5$ \\
\hline 15 & $0.75,1.75,2.25$ \\
\hline
\end{tabular}

Table 1. Selected wind direction and speeds.

\subsection{Flow simulation}

2.3.1 Optimization of building geometry: Before the mesh was generated for the CFD simulations, the building geometry was optimized for the meshing process. Otherwise small details and hidden gaps would have resulted in distorted cells and the meshing program would not have been able to generate a mesh. The first step was to use the CityDoctor tool to generate a solid CAD geometry from the CityGML file. This tool also uses the sweep-plane algorithm for the simplification of 3D building models (Piepereit et al., 2018) and to convert it into a .step-file, so it can be used by the simulation software. The final pre-processing and optimization steps were done manually as mentioned by Deininger et al. (Deininger et al., 2020). These include merging buildings to ensure that there are no hidden or small gaps between buildings, and simplifying the building geometry. In this process, the level of detail was kept higher in the important areas than in the surrounding buildings. The surrounding areas were only considered in the domain to account for their disturbance effect on the flow before it hits the relevant buildings. The outer buildings were modeled as beams or filled polygons without gaps or courtyards.

2.3.2 Simulation boundary conditions: The domain size was $1800 \times 1200 \times 1000 \mathrm{~m}$ in length, width and height. The computational mesh consisted of 2.9 million cells with a cell size of $10 \mathrm{~m}$ for the air volume. The maximum skewness was 0.93 , which is below the stability criterion of 0.95 . The height difference was $95 \mathrm{~m}$ and shows how important it is to consider the terrain in the simulations. The flow enters the area on the left, so the buildings are mostly behind the hill, which significantly affects the flow. Due to the fact, that the terrain mainly influences the flow around the buildings, the vegetation was neglected. The simulations were performed using ANSYS Fluent 

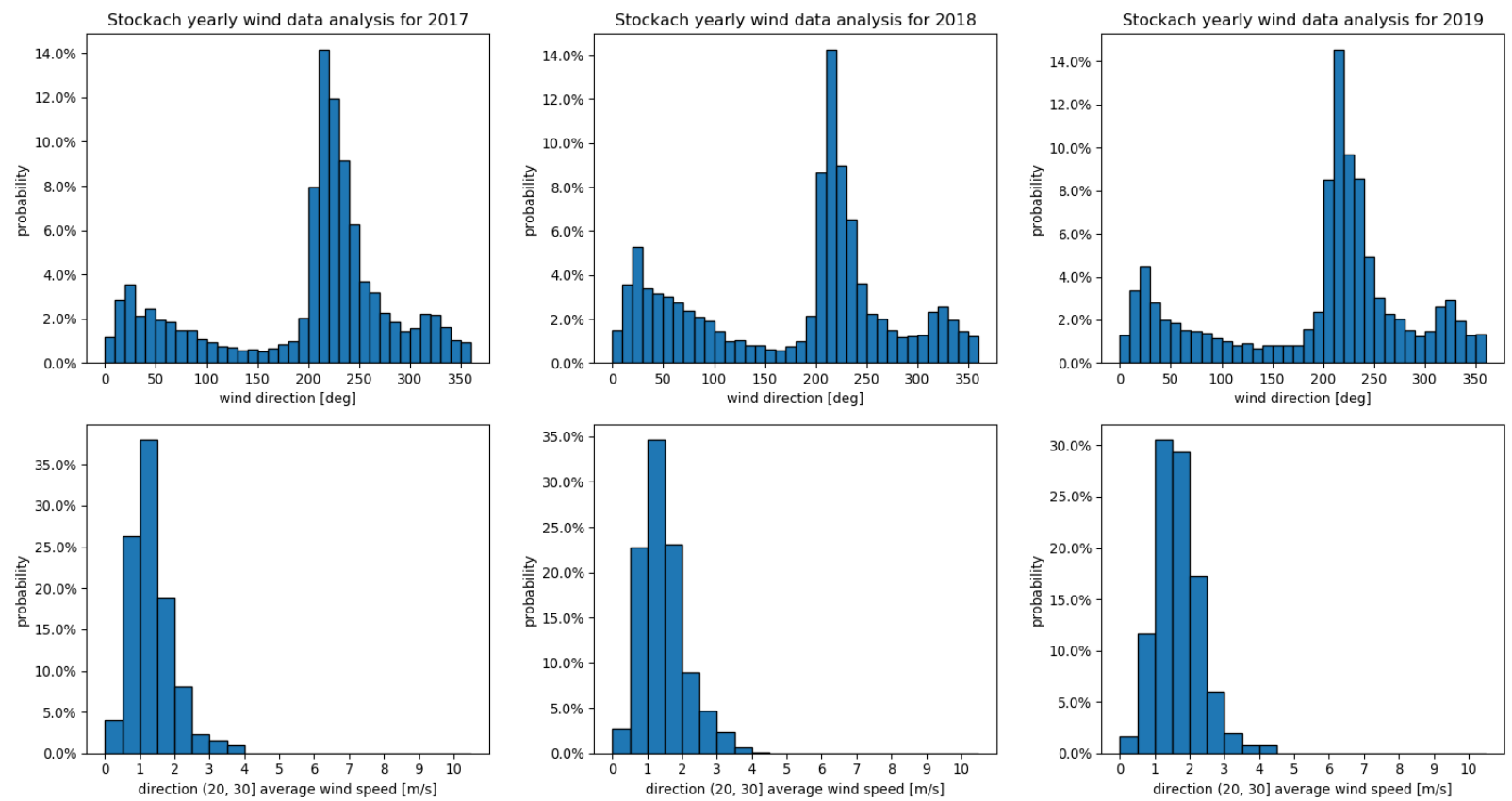

Figure 4. Annual wind direction and wind speed (for NNE direction) probabilities for the years [2017-2019] in the Stöckach area.

software as a steady-state RANS simulation with the k- $\omega$ SST turbulence model. The solid boundaries, such as buildings or terrain, were modeled as a wall boundary condition, the outlet as a pressure-outlet boundary condition, and the free surfaces as a zero-slope boundary condition. The velocity profile at the inlet was modeled as a power law with an offset defined by the following equation.

$$
U(z)=\left(\frac{z-d_{0}}{z_{r e f}-d_{0}}\right)^{\alpha} * U_{r e f}
$$

Where $U_{r e f}$ is the reference velocity measured at the reference height $z_{\text {ref }}$. The parameter $d_{0}$ is the offset height, which is 0.75 of the average building height in the urban environment. According to the previous section, the main wind direction is $215^{\circ}$, so this direction was simulated with a range of wind speeds. In winter, some of the wind comes from the $15^{\circ}$ wind direction, so this wind direction was also considered due to the higher yield in winter when the PV production is small.

\subsection{Preparation of the results for visualization}

After the CFD simulation, the results were exported and sorted by the corresponding flow lines according to the simulated wind direction. The visualization was based on the coordinates and the velocity or pressure information in the export file. Due to the local coordinate system of the results, the points had to be transformed into a higher coordinate system. In this case, this is the Gauss-Krüger zone 3 (GK3, EPSG: 31467). First, the file was transformed and colored in a Matlab script. The coordinate transition can be performed without parameters as in a classical transformation, since a transformation vector is used according to the simulation. The coloring changes the scale of the occurring velocity into a scale of RGB values as it can be seen in Figure 5.

The Java script library Cesium (Cesium GS Inc., 2021) is based on the coordinate system WGS 84 (EPSG 4326), so the Matlab

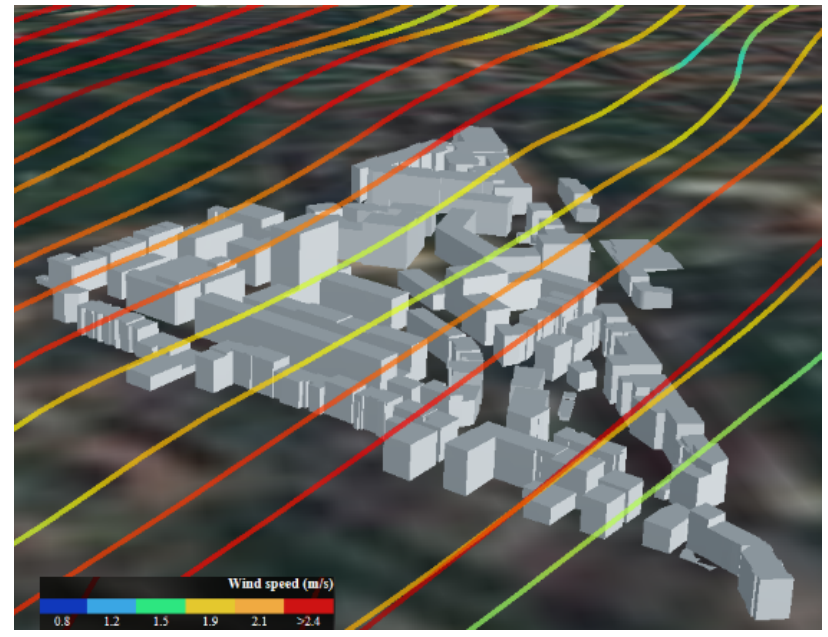

Figure 5. Visualization of the flow lines using cesium.

results had to be transformed again. The results were transformed from GK3 to WGS 84 in a Python application. This was done using stored parameter datasets. Afterwards, the data was stored in a text file containing point by point coordinates and RGB values.

\subsection{Spatio-temporal analysis}

After all simulation results were available, the simulation results were prepared for import into a relational database. Subsequently, a custom-developed server/client application was used to perform a spatio-temporal analysis that aimed to locate areas where the potential energy yield of a small wind turbine is promising and its siting is feasible. The preparation of the simulation data and the spatio-temporal analysis is described in the following steps.

2.5.1 Spatial transformation of the simulation results: Each simulation result coming from a different wind direction 
generates a vector field with a local reference system (see Figure 6). In order to orient the local Y-axis with the cartographic north direction for each simulation result an affine transformation was applied with the help of the Feature Manipulation Engine (see Figure 7).

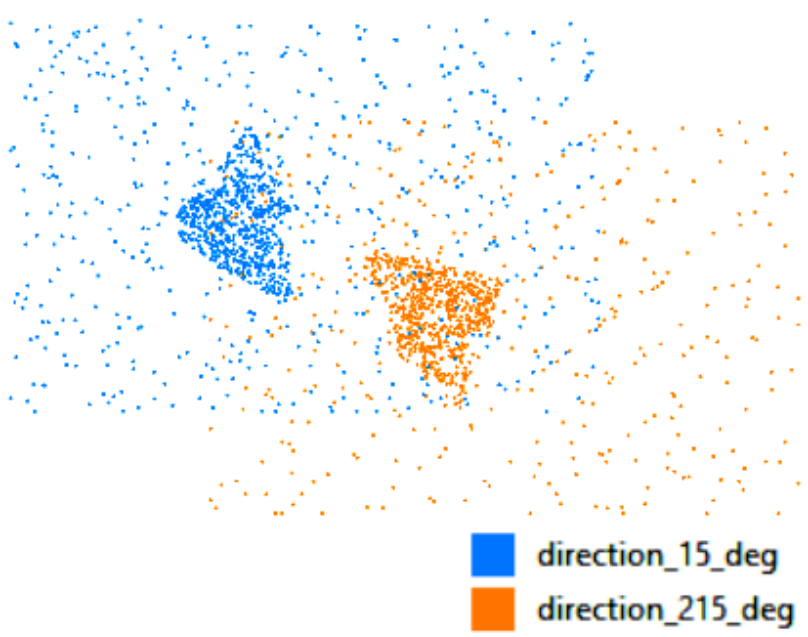

Figure 6 . Velocity fields for wind directions $15^{\circ}, 215^{\circ}$ are not registered in the same spatial reference.

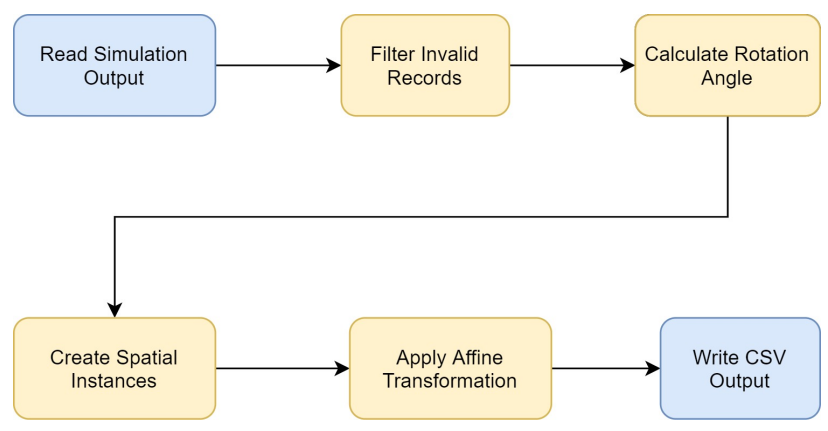

Figure 7. The conceptual model of the Feature Manipulation Engine (FME) workbench used for transforming all simulation results in the same north oriented reference system.

2.5.2 Database realization for simulation results: A relational database system was used. In this step the simulation results were reprocessed the following way:

- Providing each simulation result with a unique ID that becomes a foreign key in the database

- Creating a PostgreSQL database with the information historical measured values, simulation results and simulation conditions

- Formulate an execution plan to integrate the historical information with the simulation results and simulation conditions

- Using a visual analysis tool to locate areas with high wind energy potential

- Selecting the most promising cells (see Figure 8)

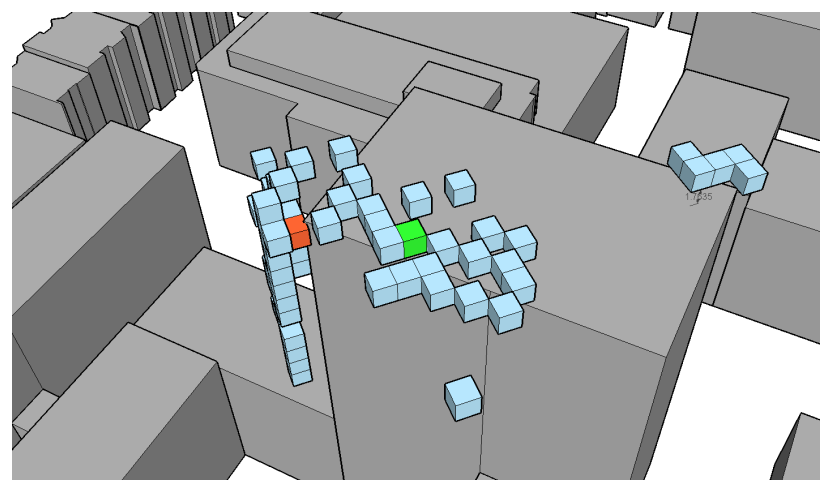

Figure 8. Visualization of the most promising cells. The green cell above the building was used to estimate the energy yield.

\subsection{Yield calculation}

Based on the promising cells defined in the previous section, time series of wind speeds were generated from the simulation results. Since the wind speeds and directions were only investigated in certain steps, missing parts of the time series are filled by interpolation. In order to enable a forecast of the PV yield at the same time, the time series was supplemented by the measured global radiation of the measuring station Stuttgart Stadtmitte. In contrast to the wind speed, the global radiation was very well transferable to the area "Neuer Stöckach". For the small wind turbines as well as for the planned PV system, a corresponding model was created in the simulation environment INSEL (Doppelintegral GmbH, 2020). For the PV system, commercially available thin-film modules were modeled. The small wind turbines were represented by a characteristic curve model.

2.6.1 Small wind turbines: The building owner limited the nominal power of the small wind turbines to be investigated to 3 $\mathrm{kW}-5 \mathrm{~kW}$. Due to a better acceptance by residents, vertical axis systems were preferred. However, these have the disadvantage that the maximum achievable energy yield is always lower than that of horizontal-axis lift based turbines that represent the most common design of wind turbines, due to their physical benefits. Figure 9 shows a comparison of different market-proven small wind turbines of the corresponding power class (Jüttemann, 2019) and the two systems TECHCARBON Helix Wind of Change and Low Wind Speed Systems 500W, which are both in the prototype stage. Except for the latter prototypes, all other systems are horizontal axis. The two prototypes are vertical axis systems with much lower rated power and were scaled up with the appropriate number of individual systems for comparison. Especially the system of the company Low Wind Speed (LWS) Systems offers very good results at low wind speeds. However, no objective evaluations could be brought into experience for this system under real operating conditions.

\section{RESULTS AND DISCUSSION}

\subsection{Methodology implementation}

Regarding data integrity, a high quality level was needed, but to be able to process the geospatial data a simplified level of detail was necessary. The reason for that was, that the meshing of the buildings might not even have been possible with a higher level of detail and not much additional information would have been gained by more detail due to the fact, that buildings can be 


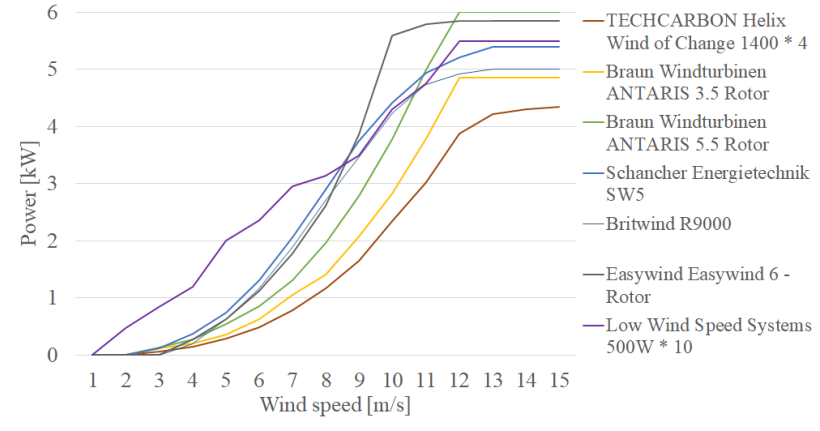

Figure 9. Comparison of small wind turbine power curves.

considered as large-scale elements where smaller details won't have a significant effect on the results.

It was chosen to simplify the models of the surrounding buildings. This has an effect on the calculated wind field. One reason for that is that porosity of the surroundings is relevant for the simulation outcome. This effect depends on wind speeds. For low wind speeds, as they occur within this site, the impact is minor. Also in our case, the topography has the larger impact. Therefor the level of detail of the surroundings was reduced for lesser computational demand, to reduce meshing errors and to improve meshing performance.

Compared to the commonly used methodology for the analysis of small wind turbine potential, on-site measurements, the presented methodology showed several advantages. First, due to the high influence on wind speed that buildings in urban areas have, several measurement stations would be needed to find a near optimal location whereas with the new methodology all potentially good locations in an entire quarter can be determined at once. Also on-site measurements would have to be taken for an entire year to give a good evaluation of the area. Finally, this methodology allows to approach potential site owners with a pre-calculated yield and thus their economic benefit without further interference which can increase acceptance.

\subsection{Wind yield}

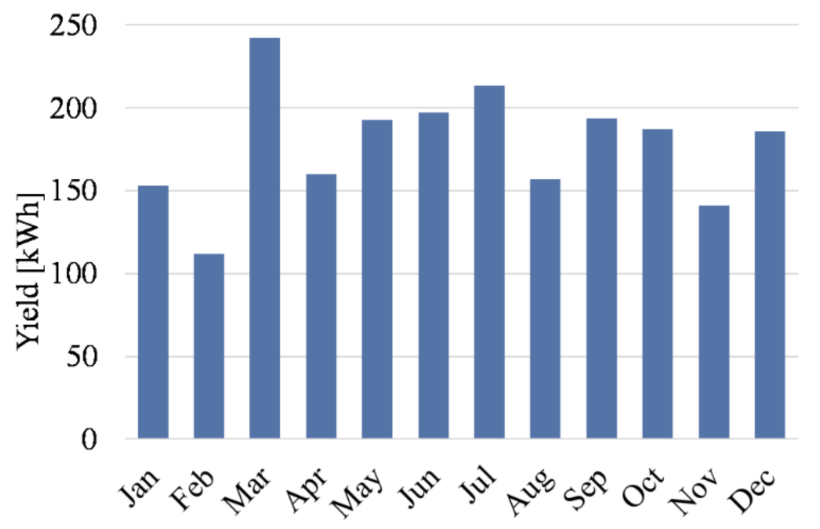

Figure 10 . Wind yield for $10 * 500 \mathrm{~W}$ LWS turbines.

Table 2 provides an overview of the wind speeds expected in "Neuer Stöckach" based on the simulation results for 2019. It can be seen that wind speeds were below $3 \mathrm{~m} / \mathrm{s}$ for almost the entire year. The average wind speed for 2019 was found to be $1.45 \mathrm{~m} / \mathrm{s}$. When comparing these wind speeds with the power curves in Figure 9, it is clear that only very low yields can be expected. In general, the systems of the considered power class that are available on the market only deliver approx. $10 \%$ of their rated power at wind speeds of $4 \mathrm{~m} / \mathrm{s}$ to $5 \mathrm{~m} / \mathrm{s}$.

\begin{tabular}{|l|l|l|l|l|l|l|l|l|}
\hline $\mathrm{WS}[\mathrm{m} / \mathrm{s}]$ & 1 & 2 & 3 & 4 & 5 & 6 & 7 & 8 \\
\hline $\mathrm{WS}[\mathrm{km} / \mathrm{h}]$ & 3.6 & 7.2 & 10.8 & 14.4 & 18 & 21.6 & 25.2 & 28.8 \\
\hline Share $[\%]$ & 31 & 50 & 16 & 3 & 0 & 0 & 0 & 0 \\
\hline Hours & 2676 & 4377 & 1373 & 282 & 40 & 11 & 2 & 1 \\
\hline
\end{tabular}

Table 2. Annual wind speed simulation results.

Only the small wind turbine from LWS Systems would, theoretically, provide a significantly larger yield here. The expected monthly balance for this system is shown in Figure 10 and would yield 2,135 kWh for 2019. For comparison, a PV system of the same installed capacity $(5 \mathrm{kWp})$ would provide two to three times the yield.

\subsection{Combined use of wind power and PV}
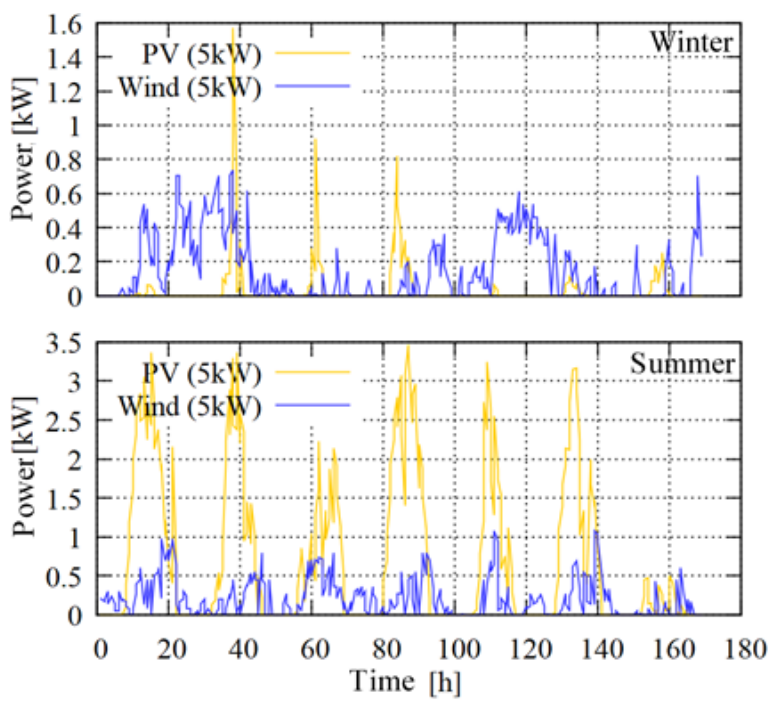

Figure 11. PV and wind power (normalized to $5 \mathrm{~kW}$ ). Winter: 01.01.2019 - 07.01.2019, Summer: 01.08.2019 - 07.08.2019.

In order to be able to compare the yield of small wind turbines and PV, the PV yields calculated for the "Neuer Stöckach" were normalized down to $5 \mathrm{kWp}$ installed capacity and compared with the yields of the LWS small wind turbine system. In Figure 11 it can be seen that small wind turbines can ensure a significantly more constant supply, which is also well suited for self-supply due to the significantly lower seasonal and daily fluctuation. However, especially in summer there can be simultaneous overproduction due to the correlation between solar irradiation and the development of wind speed that is related to emerging temperature differences.

\section{CONCLUSIONS}

Regarding the methodology, the individual steps and the entire workflow could be implemented as planned and the results considering this new approach are promising. Through the CFD simulation presented in this paper, the wind speeds of the area of the "Neuer Stöckach" were determined in 30-minute resolution for the years 2017, 2018 and 2019 and the best possible areas of the site were specified. Nevertheless the calculations for the small wind turbine potential within this specific site were less promising as they resulted in an average wind speed of 1.45 
$\mathrm{m} / \mathrm{s}$ in the best areas for the year 2019 that were used for the further calculation. This is about $18 \%$ lower than the average wind speed at the monitoring station of $1.77 \mathrm{~m} / \mathrm{s}$ which can be mainly contributed to the surrounding topography of the study area.

The average wind speed that was determined is well below the wind speed of $4 \mathrm{~m} / \mathrm{s}$ that is considered sufficient for small wind turbines. This was confirmed by the fact, that the simulations for commercially available small wind turbines $(5 \mathrm{~kW}$ power class) showed negligible yields. Only the small wind turbine from LWS Systems, assuming an installation of 10 systems of $500 \mathrm{~W}$ each, theoretically produced a relevant yield. However, this system is in prototype status and it was not possible to verify it's stated performance. Even the annual yield calculated with this system would be lower by a factor of $2-3$ than with a PV system of the same power class. It can be said that with commercially available small wind turbines, the wind strength is not sufficient to enable meaningful operation. Nevertheless, the wind and PV power complement each other well, which could be of interest when considering other locations with stronger winds.

For a future application of the methodology, it would be beneficial to reduce the steps in between the simulated wind speeds and directions to increase the accuracy. This also counteracts the problem that yield might be underestimated due to missing wind speed events in the calculated time series. This might be better realizable in future when computational performance will increase. In that context also the simulation speed could be optimized. Also more simplifications of the process are needed for it to be efficient. Here as example the amount of used programs and different simulation environments could be reduced e.g. by shifting more steps solely to Python. The computational effort can also be be minored when planning a larger amount of small wind turbines within a building cluster due to the fact, that this does not affect the simulation effort when staying in the same boundary conditions.

The outcome has also shown, that despite small wind turbines often have a lesser specific yield than PV, they have the advantage of almost seasonal independency. This is ideal for powerto-heat applications, but also for e-mobility and in that context small wind turbines could contribute more in future to the much needed decarbonisation of those sectors that are more and more electrified.

\section{ACKNOWLEDGEMENTS}

This work was funded by the Ministry of Science, Research and the Arts of Baden-Württemberg as part of the Windy Cities doctoral program and by the German Federal Ministry of Education and Research (BMBF) as part of the iCity project under the funding number 03FH9I01IA and supervised by the VDI Technologiezentrum $\mathrm{GmbH}$ on behalf of the BMBF.

\section{REFERENCES}

$\begin{array}{lccr}\text { Amt für } & \text { Umweltschutzt } & \text { Stuttgart, } & 2021 . \\ \text { Stadtklima } & \text { Stuttgart. } & \text { http://www.stadtklima- } \\ \text { stuttgart.de/index.php?luft_messdaten_download. } & \text { 2021-03-26. }\end{array}$

Bao, K., Padsala, R., Thrän, D., Schröter, B., 2020. Urban Water Demand Simulation in Residential and Non-Residential Buildings Based on a CityGML Data Model. ISPRS International Journal of Geo-Information, 9(11).
Beller, C., 2011. Urban Wind Energy. Danmarks Tekniske Universitet, Nationallaboratoriet for Bæredygtig Energi, Ris $\varnothing$, Denmark. PhD Thesis.

Brennenstuhl, M., Lust, D., Boch, P., Yadack, M., Eicker, U., 2018. The Potential of Small Wind Turbine Integration in Residential Buildings Complementing PV and Heat Pump Operation. ISEC Conference Proceedings - Renewable Heating and Cooling in Integrated Urban and Industrial Energy Systems, $331-339$.

C.A.R.M.E.N. e.V， 2020. Kleinwindenergieanlagen Hintergrundinformationen und Handlungsempfehlungen. C.A.R.M.E.N. e.V, Straubing.

Cesium GS Inc., 2021. Cesium: The Platform for 3D Geospatial. https://www.cesium.com/. 26.03.2021.

Chtibi, A., Touzani, A., 2019. Actual wind energy use situation worldwide and in Morocco: Case of small vertical axis wind turbine market offers. Proceedings of the 4th International Conference on Big Data and Internet of Things, 1-7.

Deininger, M., von der Grün, M., Piepereit, R., Schneider, S., Santhanavanich, T., Coors, V., Voß, U., 2020. A Continuous, Semi-Automated Workflow: From 3D City Models with Geometric Optimization and CFD Simulations to Visualization of Wind in an Urban Environment. ISPRS International Journal of Geo-Information, 9(11).

Doppelintegral GmbH, 2020. INSEL 8: Software for simulation, monitoring, and visualization of energy systems. https://insel.eu/. 2019-10-22.

Gehling, M., 2018. Installierte Leistung, Stromerzeugung und Marktentwicklung von Kleinwindanlagen in Deutschland. Zentrum für Sonnenergie- und Wasserstoff- Forschung BadenWürttemberg (ZSW), Stuttgart.

Jüttemann, P., 2019. Kleinwind-Marktreport Ausgabe 2020. 6. edn, Patrick Jüttemann, Bad Honnef Deutschland. www.kleinwindkraftanlagen.com.

Padsala, R., Fink, T., Peters-Anders, J., Gebetsroither-Minder, E., Coors, V., 2020. Real Corp 2019: Is This the Real World? The 25th International Conference on Urban Planning and Regional Development in the Information Society REAL CORP 2020, 365-375.

Piepereit, R., Deininger, M., Kada, M., Pries, M., Voß, U., 2018. A Sweep-Plane Algorithm for the Simplification of 3D Building Models in the Application Scenario of Wind Simulations. ISPRS - International Archives of the Photogrammetry, Remote Sensing and Spatial Information Sciences, XLII4/W10, 151-156.

Rossknecht, M., Airaksinen, E., 2020. Concept and Evaluation of Heating Demand Prediction Based on 3D City Models and the CityGML Energy ADE - Case Study Helsinki. ISPRS International Journal of Geo-Information, 9(11).

Schelmer, R., Denk, P., 2013. Vertikale Kleinwindanlagen in Bayern - Eine Wirtschaftlichkeitsanalyse. Springer Gabler, Wiesbaden.

Schneider, S., Santhanavanich, T., Koukofikis, A., Coors, V., 2020. Exploring Schemes for Visualizing Urban Wind Fields Based on CFD Simulations by Employing OGC Standards. ISPRS Ann. Photogramm. Remote Sens. Spatial Inf. Sci., VI4(W2-2020). 
Transfer portal of the University of Applied Sciences - HfT Stuttgart, 2020. https://transfer.hftstuttgart.de/gitlab/rushikesh.padsala/rhino-cityengine2citygml. 2020-08-11.

Wang, B., Sun, S., Duan, M., 2018. Wind potential evaluation with urban morphology - a case study in beijing. 5th International Conference on Energy and Environment Research, ICEER 2018, 23-27 July 2018, Prague, Czech Republic, 153, $62-67$.

Wilkinson, S., Bradbury, G., Hanna, S., 2014. Approximating Urban Wind Interference. Proceedings of the Symposium on Simulation for Architecture \& Urban Design, SimAUD '14, Society for Computer Simulation International, San Diego, CA, USA. 